\title{
Synthesis and Evaluation of Thermodynamic Solubility of Triazolo Quinolone Class Derivatives in Various Solvents at 298.15-328.15 K
}

\section{SHIPRA BALUJA*, MONA PITHIYA, ASMITA HIRAPARA and DIVYATA LAVA}

Physical Chemistry Laboratory, Department of Chemistry, Saurashtra University, Rajkot-360005, India

E-mail: shipra_baluja@rediffmail.com

Keywords: Triazolo quinolone, solubility, alcohols, ethyl acetate, thermodynamic parameters

\begin{abstract}
The solubility of triazolo quinolone class derivatives in methanol, ethanol, n-propanol, nbutanol and ethyl acetate was measured using a gravimetrical method at temperature ranging from $298.15 \mathrm{~K}$ to $328.15 \mathrm{~K}$. The results of these measurements were correlated with semi empirical equations. Some thermodynamic parameters such as. dissolution enthalpy, Gibb's free energy and entropy of mixing have also been calculated.
\end{abstract}

\section{Introduction}

Heterocyclic compounds have wide range of applications in the chemistry [1], biology [2], pharmaceuticals [3] and industries [4] etc. Triazole derivatives readily bind with a variety of enzymes and receptors in biological system via weak interactions such as coordination bonds, hydrogen bonds, ion-dipole, cation- stacking, hydrophobic effect, van der Waals force etc. and show broad spectrum of biological activities [5]. Further, it is also useful in agrochemicals [6], artificial acceptors [7] etc.

The solubility of a substance fundamentally depends on the solvent used as well as on temperature and pressure. It is one of the parameters which plays an important role in various processes $[8,9]$. For solid compounds, it plays a crucial role in the determination of proper solvents for crystallization process $[10,11]$. In organic synthesis, the knowledge of solubility of starting materials or products is useful to select appropriate solvent for reaction and to improve the purity and yield of product $[12,13]$.

In the present work, two new triazolo quinolone class derivatives were synthesized and their structures were confirmed by fundamental spectroscopic techniques. solubility of synthesized compounds has been determined in different solvents over a range of temperatures. Solubility data was correlated with temperature by using Apelblat $[14,15]$ and Buchowski-Ksiazczak $\lambda \mathrm{h}[16,17]$ models. For the better understanding of dissolution process of these compounds with different solvents, some thermodynamic parameters have also been evaluated from the solubility data.

\section{Experimental}

\subsection{Materials:}

All the chemicals used in synthesis were laboratory grade and solvents were of analytical grade.

\subsection{Synthesis:}

\subsubsection{Step-1: Synthesis of arylidene}

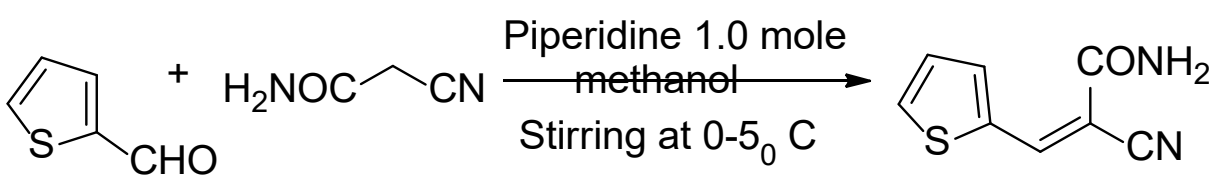




\subsubsection{Step-2: Synthesis of oxime}<smiles>CC1(C)CC(=O)CC(=O)C1</smiles>

\subsubsection{Step-3: Synthesis of MPT-1}<smiles>CC1(C)CC(=O)C/C(=N\NC(=O)c2ccncc2)C1</smiles>

Another compound was synthesized using furfural as starting material in step-1. Table 1 shows the physical parameters of synthesized compounds.

The IUPAC name of both the synthesized compounds are:

MPT-1: 8,8-dimethyl-6-oxo-2-(pyridine-4-yl)-5-(thiophene-2-yl)-1,2,6,7,8,9-hexahydro-[1,2,4]triazolo-[1,5-a]quinolone-4-carboxamide

MPT-2: $\quad$ 5-(furane-2-yl)-8,8-dimethyl-6-oxo-2-(pyridine-4-yl)-1,2,6,7,8,9-hexahydro-[1,2,4]triazolo- $[1,5-\mathrm{a}]$ quinolone-4-carboxamide.

Table 1: Physical parameters of synthesized compounds

\begin{tabular}{|c|c|c|c|c|c|}
\hline $\begin{array}{c}\text { Compound } \\
\text { Code }\end{array}$ & $\begin{array}{c}\text { Molecular } \\
\text { Weight }\end{array}$ & $\begin{array}{c}\text { Molecular } \\
\text { Formula }\end{array}$ & $\begin{array}{c}\text { \% } \\
\text { yield }\end{array}$ & $\begin{array}{c}\text { Melting } \\
\text { Point }{ }^{\mathbf{0}}\end{array}$ & $\begin{array}{c}\mathbf{R}_{\mathbf{f}} \\
\text { value }\end{array}$ \\
\hline MPT-1 & 419.49 & $\mathrm{C}_{22} \mathrm{H}_{21} \mathrm{~N}_{5} \mathrm{O}_{2} \mathrm{~S}$ & $70 \%$ & $214-216{ }^{0} \mathrm{C}$ & 0.78 \\
\hline MPT-2 & 403.49 & $\mathrm{C}_{22} \mathrm{H}_{21} \mathrm{~N}_{5} \mathrm{O}_{3}$ & $64 \%$ & $208-210{ }^{0} \mathrm{C}$ & 0.69 \\
\hline
\end{tabular}

\subsection{Characterization study:}

The structure of both the synthesized compounds were confirmed by spectroscopic techniques such as FTIR (SHIMADZU FT-IR 8400), ${ }^{1} \mathrm{H}$ NMR and ${ }^{13} \mathrm{C}$ NMR (BRUKER ADVANCE II 400 NMR) and Mass spectroscopy (Shimadzu-QP 2010 Mass spectrometer). ${ }^{1} \mathrm{H}$ NMR was taken in deuterated DMSO with TMS as a standard and it is reported in $\delta p p m$. The IR spectrum was recorded on $\mathrm{KBr}$ disc.

\subsection{Solubility measurements:}

Both the synthesized compounds were recrystallized from methanol. All the solvents used for solubility study were of HPLC grade (except ethanol) and their purity was checked by SHIMADZU GC-MS (Model No QP-2010) and was found to be greater than $99.85 \%$.

By gravimetric method, solubility of both the synthesized compounds is determined. In a solvent (methanol, ethanol, n-propanol, n-butanol and ethyl acetate), saturated solution of compound was prepared at a given temperature. The temperature of the solution was controlled by a thermostat (NOVA NV-8550 E, India) with an accuracy of $\pm 0.05 \mathrm{~K}$. At constant temperature, solution was continuously stirred for 15-30 minutes. The stirring was then stopped and solution was allowed to reach the solid-liquid equilibrium. In a pre-weighed vial, $2 \mathrm{ml}$ of upper clear solution was taken very 
carefully by a syringe and weight of vial was taken to determine the weight of solution. The solvent was then allowed to evaporate completely in a vacuum oven. When the solvent is evaporated completely, again weight of vial was taken to determine the weight of residue. The weight of the vial was recorded periodically until the weight did not change. All the masses were measured by an analytical balance (Mettler Toledo AB204-S, Switzerland) with accuracy of $\pm 0.0001 \mathrm{gm}$. Every experimental point was repeated three times and the mean values were used to calculate the mole fraction solubility.

$$
x_{i}=\frac{\left(m_{2}-m_{0}\right) / M_{1}}{\left(m_{2}-m_{0}\right) / M_{1}+\left(m_{1}-m_{2}\right) / M_{2}}
$$

where $\mathrm{M}_{1}$ and $\mathrm{M}_{2}$ are the molecular weight of compound and solvent. $m_{0}, m_{1}$ and $m_{2}$ are the weights of empty vial, weight of solution and weight of residue.

\section{Results and Discussion}

The mole fraction solubility of both the synthesized compounds are given in Table 2 at different temperatures. It is evident from the Table 2 that the mole fraction solubility increases with increasing temperature in all the solvents. Further, among alcohols, both the compounds exhibited maximum solubility in n-butanol whereas minimum solubility is observed in methanol.

Thus, solubility increases with increase the $-\mathrm{CH}_{2}$ group in alcohol. In ethyl acetate, solubility of compounds is lower and almost similar to that in methanol.

The pattern of solubility of both the synthesized compounds in different solvents is compared with the dipole moment and dielectric constant of solvents which are given in Table 3. As evident from Table 3, there is slight change in dipole moment for alcohols. Further, both dipole moment and dielectric constant decreases with increase the number of $-\mathrm{CH}_{2}$ group. Thus, solubility of both the compounds in alcohols is reverse of dielectric constant and dipole moment. For ethyl acetate, dipole moment is maximum whereas dielectric constant is minimum. Thus, for ethyl acetate, solubility is according to dielectric constant and is almost similar to methanol.

3.1. Apelblat model: The modified Apelblat equation $[14,15]$ is widely used to correlate the solubility with the temperature due to its simplicity, and it can be expressed as follows:

$$
\ln x_{i}^{a}=A+\frac{B}{T}+C \ln T
$$

where $x_{c i}^{a}$ is the calculated mole fraction solubility of compound, $\mathrm{T}$ is the absolute temperature and $\mathrm{A}, \mathrm{B}$ and $\mathrm{C}$ are empirical model parameters. The values of $\mathrm{A}$ and $\mathrm{B}$ represent the variation in the solution activity coefficient and $C$ represents the effect of temperature on the fusion enthalpy. These parameters were evaluated using least square method and are given in Table 4. Using these parameters, solubility mole fractions of both the compounds were calculated in studied solvents and are given in Table 2. Figure 1 shows the comparison of experimental solubility values with those evaluated by Apelblat model. 
Table 2: Experimental and calculated mole fraction solubility and relative deviation (RD) of both the synthesized compounds in different solvents at different temperatures

\begin{tabular}{|c|c|c|c|c|c|}
\hline $\begin{array}{c}\text { Temp. } \\
\text { (K) }\end{array}$ & $\mathrm{X}_{\mathrm{i} .10^{4}}$ & $\mathrm{x}^{\mathrm{a}}$ ci.10 & $100 R D^{a}$ & $\mathrm{x}^{\mathrm{b}}{ }_{\mathrm{ci} .10^{4}}$ & $100 R D^{b}$ \\
\hline \multicolumn{6}{|c|}{ MPT-1 } \\
\hline \multicolumn{6}{|c|}{ Methanol } \\
\hline 298.15 & 0.6471 & 0.6790 & -4.9226 & 0.8270 & -27.7969 \\
\hline 303.15 & 1.0790 & 1.0316 & 4.3921 & 1.0220 & 5.1953 \\
\hline 308.15 & 1.5103 & 1.4233 & 5.7609 & 1.2560 & 16.8060 \\
\hline 313.15 & 1.7470 & 1.7941 & -2.6942 & 1.5333 & 12.2318 \\
\hline 318.15 & 1.9842 & 2.0774 & -4.6951 & 1.8594 & 6.2890 \\
\hline 323.15 & 2.1410 & 2.2210 & -3.7385 & 2.2415 & -4.6919 \\
\hline 328.15 & 2.2972 & 2.2032 & 4.0942 & 2.6866 & -16.9504 \\
\hline \multicolumn{6}{|c|}{ Ethanol } \\
\hline 298.15 & 0.8811 & 0.8809 & -0.0049 & 0.9909 & -12.4881 \\
\hline 303.15 & 1.2950 & 1.2836 & 0.8816 & 1.2780 & 1.3141 \\
\hline 308.15 & 1.7102 & 1.7591 & -2.9339 & 1.6347 & 4.3441 \\
\hline 313.15 & 2.2790 & 2.2758 & 0.1500 & 2.0746 & 8.9700 \\
\hline 318.15 & 2.8487 & 2.7892 & 2.0918 & 2.6132 & 8.2702 \\
\hline 323.15 & 3.2200 & 3.2488 & -0.8946 & 3.2682 & -1.4974 \\
\hline 328.15 & 3.5909 & 3.6072 & -0.4518 & 4.0597 & -13.0516 \\
\hline \multicolumn{6}{|c|}{ n-Propanol } \\
\hline 298.15 & 1.4100 & 1.4166 & -0.4729 & 1.3386 & 5.0623 \\
\hline 303.15 & 1.6800 & 1.6659 & 1.1277 & 1.6708 & 0.8409 \\
\hline 308.15 & 1.9600 & 1.9962 & -1.8480 & 2.0705 & -5.6395 \\
\hline 313.15 & 2.4600 & 2.4339 & 1.0580 & 2.5483 & -3.5912 \\
\hline 318.15 & 2.9563 & 3.0163 & -2.0323 & 3.1116 & -5.4041 \\
\hline 323.15 & 3.8750 & 3.7951 & 2.0622 & 3.7865 & 2.2839 \\
\hline 328.15 & 4.7941 & 4.8453 & -1.0155 & 4.5740 & 4.5914 \\
\hline \multicolumn{6}{|c|}{ n-Butanol } \\
\hline 298.15 & 3.9986 & 4.0097 & -0.2785 & 4.2382 & -5.9932 \\
\hline 303.15 & 4.6720 & 4.6827 & -0.2279 & 4.6749 & -0.0625 \\
\hline 308.15 & 5.3461 & 5.3175 & 0.5363 & 5.1402 & 3.8523 \\
\hline 313.15 & 5.8500 & 5.8817 & -0.5420 & 5.6347 & 3.6802 \\
\hline 318.15 & 6.3539 & 6.3471 & 0.1089 & 6.1590 & 3.0689 \\
\hline 323.15 & 6.6380 & 6.6920 & -0.8133 & 6.7135 & -1.1375 \\
\hline 328.15 & 6.9218 & 6.9032 & 0.2680 & 7.2988 & -5.4465 \\
\hline \multicolumn{6}{|c|}{ Ethyl acetate } \\
\hline 298.15 & 0.6822 & 0.7048 & -3.3106 & 0.7715 & -13.0828 \\
\hline 303.15 & 0.9832 & 0.9554 & 2.8267 & 0.9526 & 3.1139 \\
\hline 308.15 & 1.2841 & 1.2351 & 3.8217 & 1.1682 & 9.0334 \\
\hline 313.15 & 1.5090 & 1.5271 & -1.1972 & 1.4232 & 5.6837 \\
\hline 318.15 & 1.7342 & 1.8106 & -4.4019 & 1.7232 & 0.6345 \\
\hline 323.15 & 2.0300 & 2.0638 & -1.6656 & 2.0742 & -2.1762 \\
\hline 328.15 & 2.3248 & 2.2668 & 2.4948 & 2.4825 & -6.7827 \\
\hline
\end{tabular}




\begin{tabular}{|c|c|c|c|c|c|}
\hline \multicolumn{6}{|c|}{ MPT-2 } \\
\hline \multicolumn{6}{|c|}{ Methanol } \\
\hline 298.15 & 7.3099 & 7.3927 & -1.1320 & 7.1618 & 2.0271 \\
\hline 303.15 & 8.3960 & 8.3044 & 1.0900 & 8.3300 & 0.7860 \\
\hline 308.15 & 9.4830 & 9.4248 & 0.6142 & 9.6414 & -1.6701 \\
\hline 313.15 & 10.8230 & 10.7987 & 0.2249 & 11.1073 & -2.6265 \\
\hline 318.15 & 12.1634 & 12.4831 & -2.6280 & 12.7392 & -4.7337 \\
\hline 323.15 & 14.6480 & 14.5498 & 0.6704 & 14.5491 & 0.6755 \\
\hline 328.15 & 17.1324 & 17.0895 & 0.2505 & 16.5489 & 3.4061 \\
\hline \multicolumn{6}{|c|}{ Ethanol } \\
\hline 298.15 & 13.2348 & 13.2282 & 0.0502 & 13.2301 & 0.0361 \\
\hline 303.15 & 15.5000 & 15.5046 & -0.0300 & 15.5138 & -0.0888 \\
\hline 308.15 & 17.7643 & 18.0828 & -1.7929 & 18.0979 & -1.8781 \\
\hline 313.15 & 21.1360 & 20.9900 & 0.6907 & 21.0089 & 0.6015 \\
\hline 318.15 & 24.5069 & 24.2549 & 1.0280 & 24.2740 & 0.9503 \\
\hline 323.15 & 28.0450 & 27.9073 & 0.4911 & 27.9215 & 0.4405 \\
\hline 328.15 & 31.5835 & 31.9778 & -1.2484 & 31.9803 & -1.2563 \\
\hline \multicolumn{6}{|c|}{ n-Propanol } \\
\hline 298.15 & 10.3246 & 10.3509 & -0.2548 & 10.9397 & -5.9578 \\
\hline 303.15 & 12.5540 & 12.5569 & -0.0228 & 12.5328 & 0.1692 \\
\hline 308.15 & 14.7842 & 14.7931 & -0.0606 & 14.2946 & 3.3112 \\
\hline 313.15 & 16.9290 & 16.9544 & -0.1499 & 16.2359 & 4.0943 \\
\hline 318.15 & 19.0739 & 18.9349 & 0.7284 & 18.3671 & 3.7056 \\
\hline 323.15 & 20.3050 & 20.6381 & -1.6407 & 20.6988 & -1.9396 \\
\hline 328.15 & 22.1112 & 21.9849 & 0.5710 & 23.2419 & -5.1134 \\
\hline \multicolumn{6}{|c|}{ n-Butanol } \\
\hline 298.15 & 14.0465 & 14.0364 & 0.0716 & 14.4289 & -2.7227 \\
\hline 303.15 & 16.9220 & 16.9099 & 0.0711 & 16.9037 & 0.1082 \\
\hline 308.15 & 19.7979 & 20.0228 & -1.1358 & 19.7014 & 0.4874 \\
\hline 313.15 & 23.3500 & 23.3259 & 0.1033 & 22.8502 & 2.1406 \\
\hline 318.15 & 26.9013 & 26.7604 & 0.5239 & 26.3789 & 1.9418 \\
\hline 323.15 & 30.2590 & 30.2598 & -0.0027 & 30.3176 & -0.1937 \\
\hline 328.15 & 33.6163 & 33.7532 & -0.4073 & 34.6969 & -3.2147 \\
\hline \multicolumn{6}{|c|}{ Ethyl acetate } \\
\hline 298.15 & 7.9390 & 8.0387 & -1.2563 & 7.5577 & 4.8030 \\
\hline 303.15 & 8.4450 & 8.3440 & 1.1959 & 8.3738 & 0.8430 \\
\hline 308.15 & 8.9510 & 8.8807 & 0.7853 & 9.2472 & -3.3096 \\
\hline 313.15 & 9.7040 & 9.6762 & 0.2867 & 10.1795 & -4.8997 \\
\hline 318.15 & 10.4580 & 10.7768 & -3.0484 & 11.1719 & -6.8263 \\
\hline 323.15 & 12.3500 & 12.2517 & 0.7957 & 12.2258 & 1.0054 \\
\hline 328.15 & 14.2420 & 14.1991 & 0.3014 & 13.3425 & 6.3158 \\
\hline
\end{tabular}

$x_{c i}^{a}$ and $x_{c i}^{b}$ are calculated values from Apelblat and $\lambda \mathrm{h}$ models.

3.2. Buchowski-Ksiazczak $\lambda \mathbf{h}$ model: The Buchowski-Ksiazczak $\lambda$ h equation $[16,17]$ describes the solid-liquid equilibrium by using only two parameter $\lambda$ and $h$. The Buchowski-Ksiazcak equation is: 


$$
\ln \left[1+\frac{\lambda\left(1-X_{c i}^{b}\right)}{X_{c i}^{b}}\right]=\lambda h\left[\frac{1}{T}-\frac{1}{T_{m}}\right]
$$

where $\mathrm{T}$ and $\mathrm{T}_{\mathrm{m}}$ are the experimental temperature and melting temperature respectively. $\lambda$ and $\mathrm{h}$ are the adjustable parameters. $x_{c i}^{b}$ is the calculated mole fraction solubility. The evaluated values of $\lambda$ and $\mathrm{h}$ are given in Table 5. Using these parameters, solubility mole fractions of both the compounds were calculated in studied solvents and are given in Table 2. Figure 2 shows the comparison of experimental solubility values with those evaluated by Buchowski-Ksiazczak $\lambda \mathrm{h}$ model.

The relative deviation (RD), root mean square deviation (RMSD) and average relative deviation (ARD) were used to assess the fitting degree and applicability of these two models to the experiment values and were calculated by following equations:

$$
\begin{gathered}
R D=\frac{\left(x_{i}-x_{c i}\right)}{x_{i}} \\
R M S D=\left[\sum_{i=1}^{N} \frac{\left(x_{c i}-x_{i}\right)^{2}}{N-1}\right]^{\frac{1}{2}} \\
A R D=\frac{1}{N} \sum_{i}^{N} \frac{\left(x_{i}-x_{c i}\right)}{x_{i}}
\end{gathered}
$$

where $x_{i}$ and $x_{c i}$ are experimental and calculated value of the solubility mole fraction of the compound, $\mathrm{N}$ is the number of experimental points. The RD values for both models are given in Table 2 whereas RMSD and ARD values are listed in Table 6. It is evident from Table 6 that the solubility evaluated by Apelblat model is better than that evaluated by Buchowski-Ksiazczak model.

Table 3: Dipole moment and Dielectric constant of solvents

\begin{tabular}{|c|c|c|}
\hline Solvents & Dipole moment & Dielectric constant \\
\hline Methanol & 1.70 & 32.70 \\
\hline Ethanol & 1.69 & 24.55 \\
\hline n-Propanol & 1.68 & 20.33 \\
\hline n-Butanol & 1.66 & 17.50 \\
\hline Ethyl acetate & 1.78 & 6.02 \\
\hline
\end{tabular}

Table 4: The Apelblat coefficients A, B, C and correlation coefficient $(\gamma)$ for both the compounds in different solvents

\begin{tabular}{|c|c|c|c|c|}
\hline \multicolumn{5}{|c|}{ MPT-1 } \\
\hline Solvents & A & B & C & $\gamma$ \\
\hline Methanol & 2089.777 & -100542.22 & -309.281 & 0.994 \\
\hline Ethanol & 1243.577 & -61952.35 & -183.433 & 0.9995 \\
\hline n-Propanol & -599.911 & 24007.13 & 89.604 & 0.9994 \\
\hline n-Butanol & 577.115 & -28606.72 & -85.8241 & 0.9997 \\
\hline Ethyl acetate & 950.172 & -47698.83 & -140.366 & 0.9971 \\
\hline \multicolumn{5}{|c|}{ MPT-2 } \\
\hline Methanol & -351.561 & 13651.144 & 52.4017 & 0.9991 \\
\hline Ethanol & -1.61361 & -2664.0956 & 0.68798 & 0.9995 \\
\hline n-Propanol & 582.076 & -29371.299 & -86.0783 & 0.9996 \\
\hline n-Butanol & 286.311 & -15991.27 & -41.9907 & 0.9999 \\
\hline Ethyl acetate & -663.404 & 28849.243 & 98.2021 & 0.9975 \\
\hline
\end{tabular}


Table 5: $\lambda$ and h parameters of Buchowski-Ksiazczak and correlation coefficient $(\gamma)$ for both the compounds in different solvents

\begin{tabular}{|c|c|c|c|c|c|c|}
\hline & \multicolumn{3}{|c|}{ MPT-1 } & \multicolumn{3}{c|}{ MPT-2 } \\
\hline Solvents & $\lambda$ & h. $10^{-5}$ & $\Gamma$ & $\lambda$ & h.10 & $\gamma$ \\
\hline Methanol & 0.0125 & 3.0811 & 0.994 & 0.0236 & 1.1563 & 0.9991 \\
\hline Ethanol & 0.0401 & 1.1460 & 0.9995 & 0.0527 & 0.5465 & 0.9995 \\
\hline n-Propanol & 0.0250 & 1.601 & 0.9994 & 0.0254 & 0.9671 & 0.9996 \\
\hline n-Butanol & 0.0043 & 4.1351 & 0.9997 & 0.0562 & 0.5091 & 0.9999 \\
\hline Ethyl acetate & 0.0112 & 3.4116 & 0.9971 & 0.0081 & 2.2872 & 0.9975 \\
\hline
\end{tabular}

\subsection{Thermodynamic parameters:}

The dissolution of compound in a solvent is associated with changes in thermodynamic functions such as enthalpy $\left(\Delta H_{s o l}\right)$, Gibb's energy $\left(\Delta G_{s o l}\right)$ and entropy of solution $\left(\Delta S_{\text {sol }}\right)$.

The enthalpies of solution $\left(\Delta H_{s o l}\right)$ was calculated by modified Van't Hoff equation [18] i.e., from the slope of the plot of $\ln x$ versus $\left(1 / T-1 / T_{h m}\right)$.

$$
\left[\frac{\partial \ln x_{i}}{\partial\left(\frac{1}{T}-\frac{1}{T_{h m}}\right)}\right]_{p}=-\frac{\Delta H_{\text {sol. }}}{R}
$$

where $T$ is the experimental temperature, $T_{m}$ is mean harmonic temperature [19] and $R$ is universal gas constant $(8.314 \mathrm{~J} / \mathrm{mol} \mathrm{K})$.

The harmonic temperature is calculated by the relation:

$$
T_{h m}=\frac{n}{\sum_{i=1}^{n}\left(\frac{1}{T}\right)}
$$

where $\mathrm{n}$ is the number of temperatures analyzed. In the present study, harmonic temperature is $312.83 \mathrm{~K}$.

The change in Gibb's free energy $\left(\Delta \mathrm{G}_{\text {sol }}\right)$ during solubility process can be calculated by intercept of the plot of $\ln x_{i}$ versus $\left(1 / T-1 / T_{h m}\right)$ by following equation:

$$
\Delta G_{\text {sol. }}=-R \times T_{h m} \times \text { Intercept }
$$

Finally, the entropy of solution $\left(\Delta S_{\text {sol }}\right)$ was obtained from these evaluated $\Delta H_{\text {sol }}$ and $\Delta \mathrm{G}_{\text {sol }}$ values at $T_{h m}[20]$.

$$
\Delta S_{\text {sol. }}=\frac{\Delta H_{\text {sol. }}-\Delta G_{\text {sol. }}}{T_{h m}}
$$

The calculated thermodynamic parameters are listed in Table 7 for both the compounds in studied solvents. It is observed that both enthalpy and Gibb's free energy of dissolution are positive in all the solvents for both the compounds. However, entropy values are both positive and negative.

Comparison of solubility data with Gibb's energy values shows that these two are inversely related. As solubility increases, Gibb's energy decreases. The lower Gibb's free energy corresponds to stronger interaction between solute and solvent which results to higher solubility. The positive $\Delta G_{s o l}$ indicates that the dissolution process is spontaneous whereas positive enthalpy of dissolution $\left(\Delta H_{s o l}\right)$ indicates endothermic dissolution process. This may be due to the powerful interaction between compounds and solvent molecules than those between the solvent-solvent and compound- 
compound molecules. Thus, the newly formed bond energy between compound and solvent molecule is not powerful enough to compensate the energy needed for breaking the original association bond in various solvents. The positive entropy of dissolution suggests that the entropy of solubilization is more favorable, whereas negative entropy is due to more order in solutions [21]. The thermodynamic studies will help to optimize the dissolution of studied compounds in different solvents.

Table 6: Root mean square deviation (RMSD) and relative average deviation (ARD) values of both the synthesized compounds for both models in different solvents

\begin{tabular}{|c|c|c|c|c|}
\hline Solvents & \multicolumn{2}{|c|}{ Apelblat } & \multicolumn{2}{c|}{ Buchowski } \\
\hline & RMSD.10 & ARD.10 & RMSD.10 & ARD.10 \\
\hline & \multicolumn{4}{|c|}{ MPT-1 } \\
\hline Methanol & 0.79 & -0.258 & 2.32 & -1.274 \\
\hline Ethanol & 0.35 & -0.167 & 2.37 & -0.591 \\
\hline n-Propanol & 0.50 & -0.16 & 1.34 & -0.265 \\
\hline n-Butanol & 0.30 & -0.135 & 2.35 & -0.291 \\
\hline Ethyl acetate & 0.49 & -0.205 & 0.97 & -0.511 \\
\hline & \multicolumn{5}{|c|}{ MPT-2 } \\
\hline Methanol & 1.49 & -0.130 & 3.68 & -0.305 \\
\hline Ethanol & 2.45 & -0.116 & 2.43 & -0.171 \\
\hline n-Propanol & 1.57 & -0.118 & 7.11 & -0.247 \\
\hline n-Butanol & 1.22 & -0.111 & 5.55 & -0.208 \\
\hline Ethyl acetate & 1.52 & -0.134 & 5.47 & -0.295 \\
\hline
\end{tabular}

Table 7: Thermodynamic parameters for both the synthesized compounds in different solvents

\begin{tabular}{|c|c|c|c|c|c|c|}
\hline & \multicolumn{3}{|c|}{ MPT-1 } & \multicolumn{3}{c|}{ MPT-2 } \\
\hline Solvents & $\begin{array}{c}\Delta \mathrm{H} \\
(\mathrm{KJ} / \mathrm{mole})\end{array}$ & $\begin{array}{c}\Delta \mathrm{G} \\
(\mathrm{KJ} / \mathrm{mole})\end{array}$ & $\begin{array}{c}\Delta \mathrm{S} \\
(\mathrm{J} / \mathrm{mole})\end{array}$ & $\begin{array}{c}\Delta \mathrm{H} \\
(\mathrm{KJ} / \mathrm{mole})\end{array}$ & $\begin{array}{c}\Delta \mathrm{G} \\
(\mathrm{KJ} / \mathrm{mole})\end{array}$ & $\begin{array}{c}\Delta \mathrm{S} \\
(\mathrm{J} / \mathrm{mole})\end{array}$ \\
\hline Methanol & 31.95 & 22.88 & 28.99 & 22.72 & 17.72 & 15.96 \\
\hline Ethanol & 38.25 & 22.10 & 51.61 & 23.93 & 16.06 & 25.16 \\
\hline n-Propanol & 33.32 & 21.56 & 37.60 & 20.43 & 16.73 & 11.85 \\
\hline n-Butanol & 14.74 & 19.47 & -15.14 & 23.79 & 15.84 & 25.42 \\
\hline Ethyl acetate & 31.69 & 23.07 & 27.55 & 15.41 & 17.94 & -8.06 \\
\hline
\end{tabular}



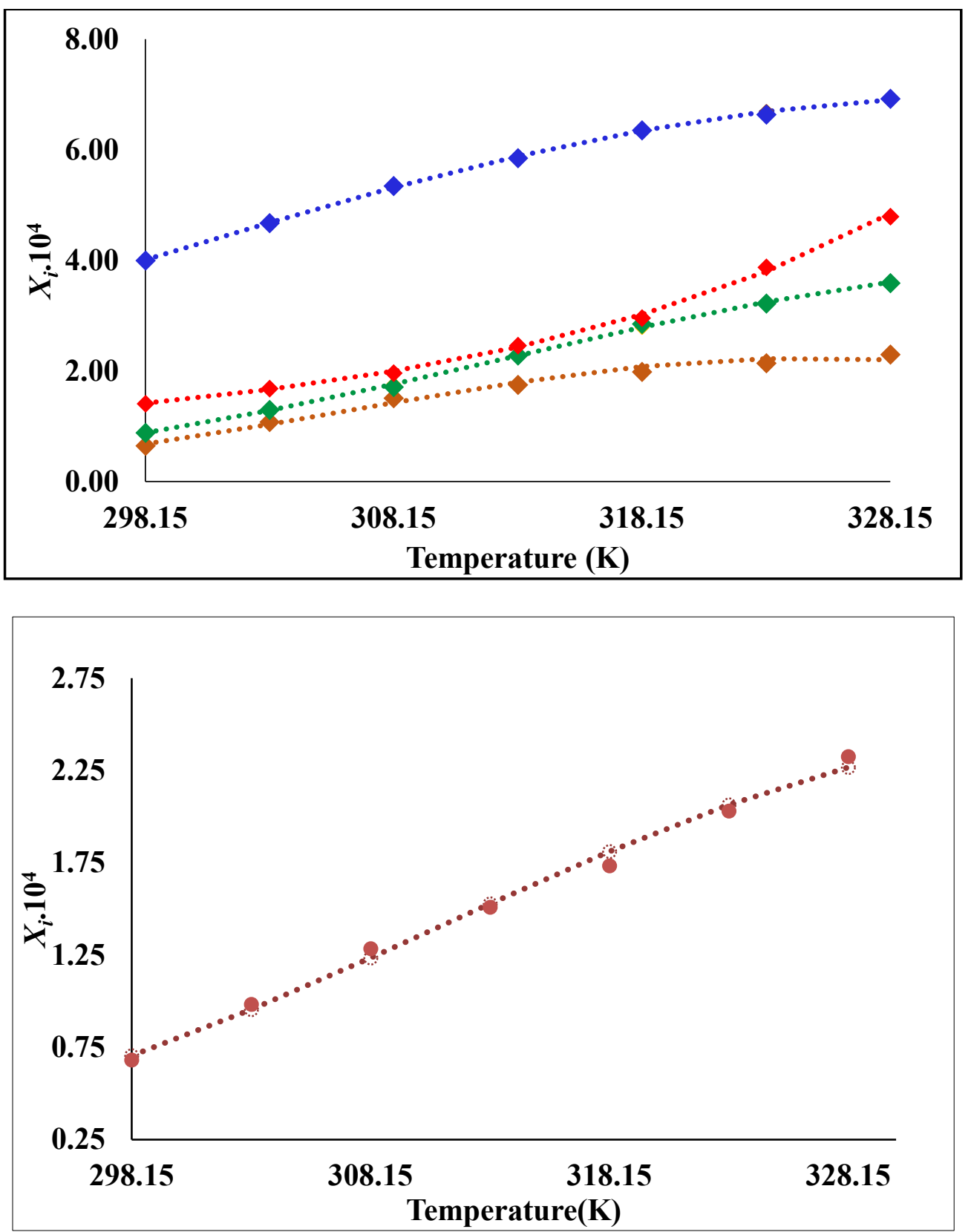

Figure 1: The variation of experimental mole fraction solubility $\left(\mathrm{x}_{\mathrm{i}}\right)$ with temperature for

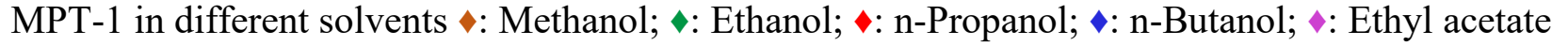
Corresponding dotted lines (...) are for calculated mole fraction solubility $\mathrm{x}_{\mathrm{ci}}^{\mathrm{a}}$ by Apelblat model 

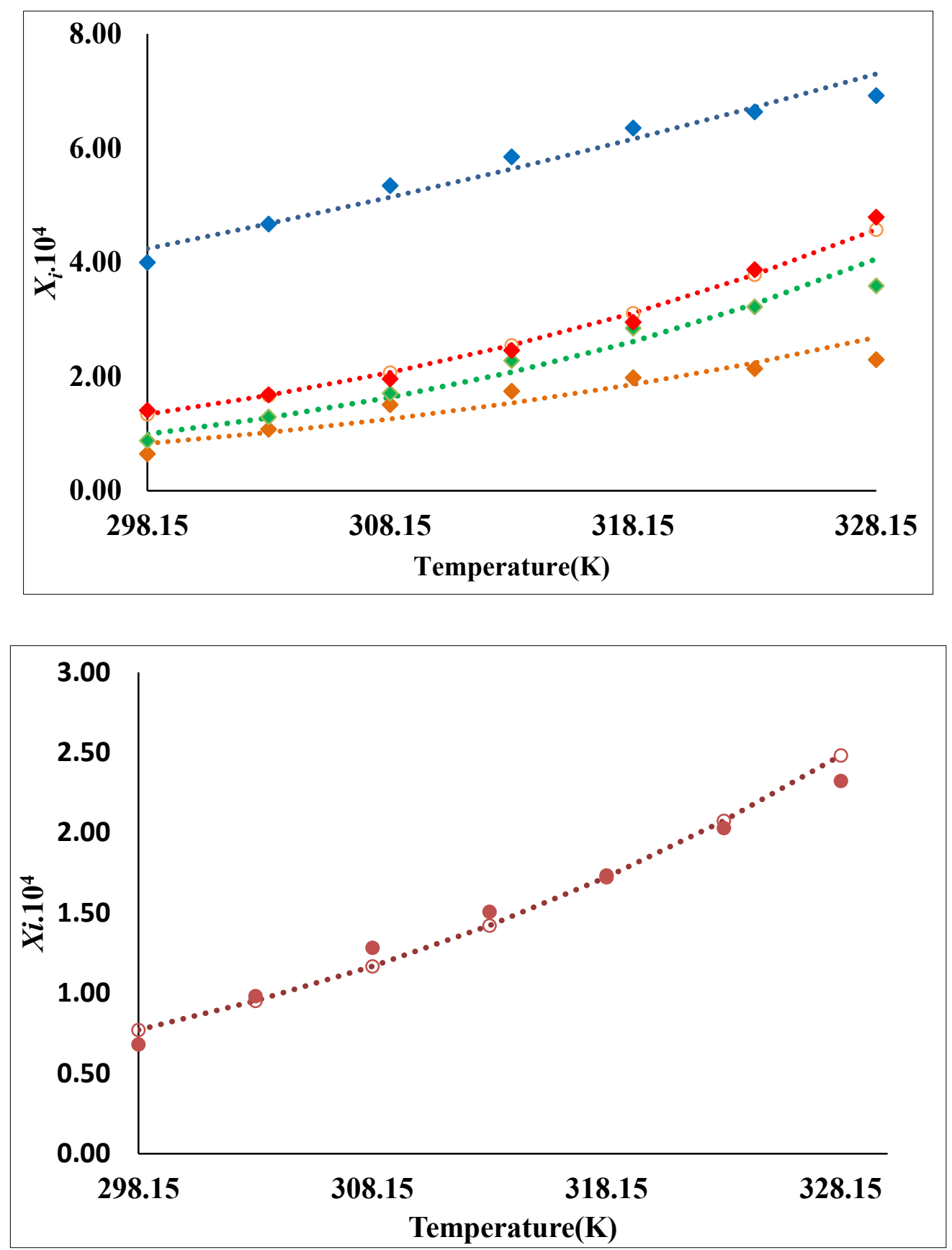

Figure 2: The variation of experimental mole fraction solubility $\left(x_{i}\right)$ with temperature for MPT-2 in different solvents $\diamond$ : Methanol; $\triangleleft$ : Ethanol; $\diamond$ : n-Propanol; $\diamond$ : n-Butanol; $\triangleleft$ : Ethyl acetate Corresponding dotted lines $(. .$.$) are for calculated mole fraction solubility x_{c i}^{b}$ by BuchowskiKsiazczak model

\section{Conclusions}

The mole fraction solubility of both the synthesized compounds increase with increasing temperature in all the solvents. Among alcohols, solubility increases with increase the $-\mathrm{CH}_{2}$ group in alcohol. In ethyl acetate, solubility of compounds is lower and almost similar to that in methanol. The solubility evaluated by Apelblat model is better than that evaluated by Buchowski-Ksiazczak model. The thermodynamic parameters indicate spontaneous endothermic dissolution process

\section{Conflict of Interest}

There is no conflict of interest. 


\section{Acknowledgments}

Authors are thankful to Head of Chemistry department for providing necessary facilities.

\section{References}

[1] Riener K., Haslinger S., Raba A., Högerl M., Cokoja M., Herrmann W. and Kuhn F., Chemistry of iron N-heterocyclic carbene complexes: syntheses, structures, reactivities, and catalytic applications. Chem. Rev. 2014;114:5215-5272.

[2] Medina F., Marrero J., Alonso M., Gonzalez M., Guerrero I., Garcia A. and Robles S. Coumarin heterocyclic derivatives: chemical synthesis and biological activity. Nat. Prod. Rep. 2015;32:1472-1507.

[3] Zhou Y., Wang J., Gu Z., Wang S., Zhu W., Acena J., Soloshonok V., Izawa K. and Liu H. Next generation of fluorine-containing pharmaceuticals, compounds currently in phase II-III clinical trials of major pharmaceutical companies: new structural trends and therapeutic areas. Chem. Rev. 2016;116:422-518.

[4] Daoud D., Douadi T., Hamani H., Chafaa S. and Al-Noaimi M. Corrosion inhibition of mild steel by two new S-heterocyclic compounds in $1 \mathrm{M} \mathrm{HCl}$ : experimental and computational study. Corr. Sci. 2015;94:21-37.

[5] Rai M., Kon K., Ingle A., Duran N., Galdiero S. and Galdiero M. Broad-spectrum bioactivities of silver nanoparticles: the emerging trends and future prospects. Appl. Microb. Biotechn. 2014;98:1951-1961.

[6] Guan A., Liu C., Sun X., Xie Y. and Wang M. Discovery of pyridine-based agrochemicals by using intermediate derivatization methods. Bioorg. Med. Chem. 2016;24:342-353.

[7] Zhang B. and Studer A. Recent advances in the synthesis of nitrogen heterocycles via radical cascade reactions using isonitriles as radical acceptors. Chem. Soc. Rev. 2015;44:3505-3521.

[8] Savjani T., Anuradha K. and Savjani K. Drug Solubility: Importance and Enhancement Techniques. ISRN Pharma, 2012:1-10.

[9] Reginald P. and Tomkins T. Applications of Solubility Data. J. Chem. Educ. 2008;85:310318.

[10] Wu J., Ge J., Zhang Y., Yu Y. and Zhang X. Solubility of genistein in water, methanol, ethanol, prop-2-ol, 1-butanol and ethyl acetate from (280 to 333) K. J. Chem. Eng. Data. 2010;55:5286-5288.

[11] Pankaj J. and Murthy Z. Solubility and crystal size of sirolimus in different organic solvents. J. Chem. Eng. Data. 2010;55:5050-5054.

[12] Zala S., Patel K., Patel K., Parmar J. and Sen D. Laboratory techniques of purification and isolation. Int. J. Drug. Dev. Res. 2012;4:41-55.

[13] Welton T. Solvent and sustainable Chemistry. Proc. Royel Soc. 2015;(A)471:1-26.

[14] Apelblat A. and Manzurola E. Solubility of oxalic, malonic, succinic, adipic, maleic, malic, citric and tartaric acid in water from 278.15-338.15 K. J. Chem. Thermodyn. 1999;31:85-91.

[15] Manzurola E. and Apelblat A. Solubilities of 1-glutamic acid, 3-nitrobenzoic acid, p-toluic acid, calcium-l-lactate, calcium gluconate, magnesium-dl-aspartate, and magnesium-l-lactate in water. J. Chem. Thermodyn. 2002;34:127-1136.

[16] Buchowski H., Ksiazczak A. and Pietrzyk S. Solvents activity along the Saturation line and solubility. J. Phys. Chem. 1980;84:975-970. 
[17] Buchowski H., Kosinski J., and Ksiazczak A. Activity of solvent and solubility. J. Phys. Chem. 1988;92:6104-6107.

[18] Krug R., Hunter W. and Grieger R. Enthalpy entropy compensation. 2. Separation of the chemical from the statistical effects. J. Phys. Chem. 1976;80:2341-2351.

[19] Meng Z., Hu Y., Kai Y., Yang W., Cao Z. and Shen F. Thermodynamics of solubility of thiomalic acid in different organic solvents from $278.15 \mathrm{~K}$ to $333.15 \mathrm{~K}$. Fluid Phase Equilib. 2013;352:1-6.

[20] Martin A., Physical Pharmacy, 4th edn., Lippincott Williams \& Wilkins, Baltimore, USA, (1993).

[21] El-Bindary A., El-Sonbati A., El-Mosalamy E. and Ahmed R. Potentiometric and thermodynamic studies of azosulfonamide drugs X. Chem. Pap. 2003;57:255-258. 